\title{
Congenital cystic adenomatoid malformation in a middle-aged woman with hemoptysis
}

Iskander Al-Githmi, MD, FRCSC, Hassan Kanaan, MD, Nadia Batawil, MD, and Irfan Mamoun, MD, Jeddah, Saudi Arabia

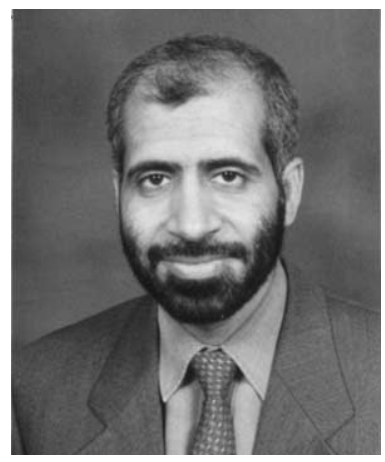

Al-Githmi

ongenital cystic adenomatoid malformation (CCAM) is a rare pulmonary malformation that mostly affects newborn infants. Some of the lesions may be delayed until school age and adolescence. It usually is seen in the form of repeated respiratory tract infection. We report a case of CCAM type 1 (Stocker classification) with a presentation of hemoptysis.

\section{Clinical Summary}

A 42-year-old woman with no previous history of respiratory problems sought treatment for recurrent hemoptysis and exertional shortness of breath. Results of the physical examination were unremarkable except for a right thyroid nodule. A high-resolution computed tomographic scan of the chest showed honeycomb bronchiectatic changes of moderate degree involving the lower lobe of the left lung (Figure 1). Results of transthoracic echocardiography, pulmonary function tests, and bronchoscopy were unremarkable. A sample obtained from the right thyroid nodule by fine-needle aspiration showed follicular adenoma.

The patient underwent left thoracotomy and a left lower lobectomy. The gross pathologic examination with serial sectioning revealed multiple small cysts near the main bronchus, with the largest measuring $1.5 \mathrm{~cm}$. The rest of the lung parenchyma was unremarkable. Histologic examination revealed multiple cysts measuring as large as $1.5 \mathrm{~cm}$ and lined with pseudostratified ciliated epithelium with multiple interspersed mucus cells (Figure 2, $B$ and $C$ ) associated with smooth muscle, focal cartilage (Figure 2, A), and multiple neuroendocrine nests ("tumorlets," Figure 2,

From the Department of Cardiovascular Diseases, King Faisal Specialist Hospital \& Research Center, Jeddah, Saudi Arabia.

Received for publication Nov 14, 2003; revisions received Jan 5, 2004; accepted for publication Jan 8, 2004.

Address for reprints: Iskander Al-Githmi, MD, FRCSC, Department of Cardiovascular Diseases, King Faisal Specialist Hospital \& Research Center, MBC-J16, Jeddah 21499, Saudi Arabia (E-mail: algithmi@hotmail. com).

J Thorac Cardiovasc Surg 2004;127:1833-4

$0022-5223 / \$ 30.00$

Copyright (C) 2004 by The American Association for Thoracic Surgery

doi:10.1016/j.jtcvs.2004.01.011

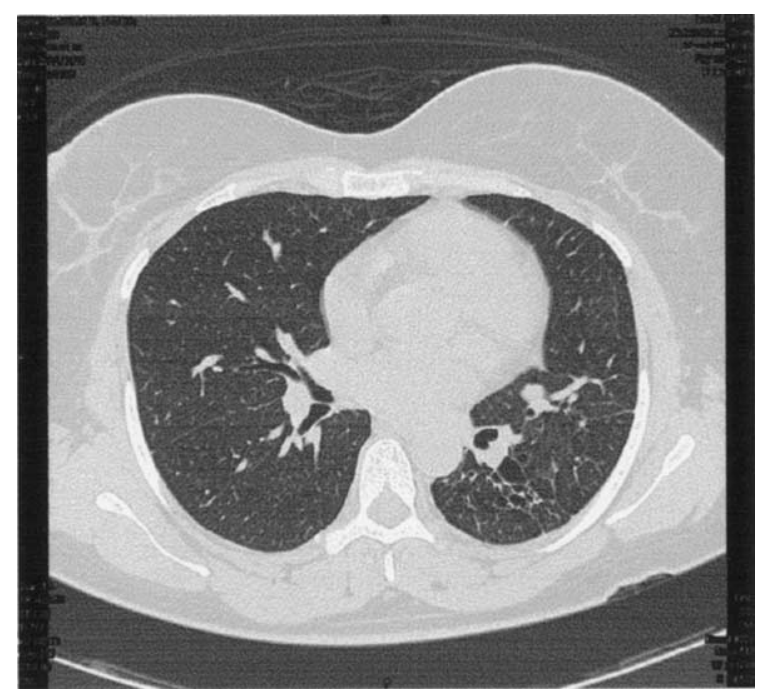

Figure 1. Bronchiectatic changes of superior segment of left lower lobe.

$D$ ). The postoperative course was uneventful, and the patient was discharged to her home and is doing well.

\section{Discussion}

The term congenital cystic adenomatoid malformation was introduced in $1949 .{ }^{1}$ Stocker and coworkers ${ }^{2,3}$ described four types of CCAMs, differentiating by the size of the cysts and structures. Type 0 was defined as bronchial, type 1 as bronchial/bronchiolar, type 2 as bronchiolar, type 3 as bronchiolar/alveolar duct, and type 4 as peripheral.

CCAM of the lung is an embryonic anomaly resulting from excessive overgrowth of the terminal bronchioles. It is usually unilateral, but it can be bilateral. It mostly affects newborn infants, and only rarely is the lesion delayed beyond adolescence. The main clinical presentation is repeated respiratory tract infection. Lung abscess in adulthood has been described. ${ }^{4}$ CCAM's potential for malignant transformation (to bronchoalveolar carcinoma and pulmonary embryonic rhabdomyosarcoma) has been described. ${ }^{5,6}$ To our knowledge, however, the case presented here is an extremely rare clinical scenario. 


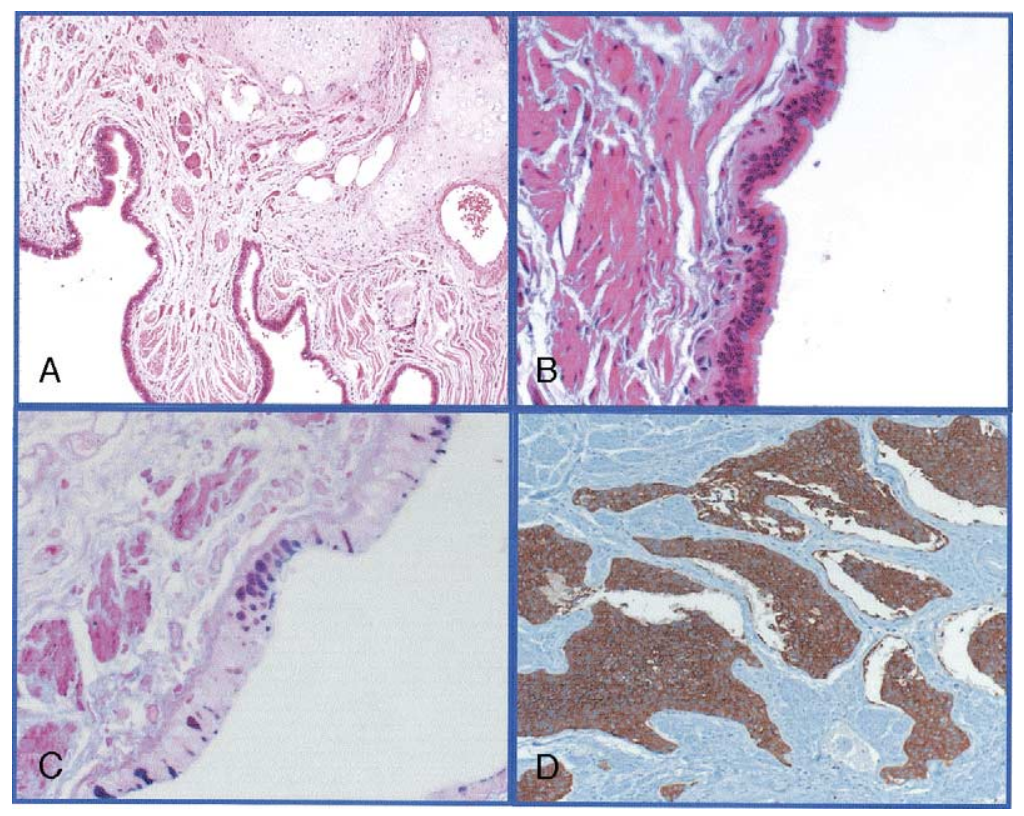

Figure 2. A, Cartilage and smooth muscle bundles (hematoxylin and eosin stain). B, Pseudostratified ciliated epithelium (hematoxylin and eosin stain). C, Mucus-secreting cells are highlighted by Alcian blue/periodic acid-Schiff stain. D, Neuroendocrine nests stain strongly positively for chromogranin A antibody.

We believe that because of CCAM's malignant potential, repeated respiratory infection, and risk of bleeding, surgical exploration is imperative even if the patient has no symptoms.

\section{References}

1. Chi' in KY, Tang MY. Congenital cystic adenomatoid malformation of one lobe of a lung with general anasarca. Arch Pathol. 1949;47: 221-9.

2. Stocker JT, Madewell JE, Drake RM. Congenital cystic adenomatoid malformation of the lung: classification and morphologic spectrum. Hum Pathol. 1977;2:155-71.

3. Stocker JT. Congenital airway malformation: a new name and an expanded classification of congenital cystic adenomatoid malformation of the lung. Histopathology. 2002;41(Suppl):424-31.

4. Dahabreh J, Zisis C, Vassiliou M, Amogiannki N. Congenital cystic adenomatoid malformation in adult presenting as lung abscess. Eur J Cardiothorac Surg. 2000;18:720-3.

5. de Perrot M, Pache JC, Spiliopoulos A. Carcinoma arising in congenital lung cysts. Thorac Cardiovasc Surg. 2001;49:184-5.

6. Kaslovsky RA, Purdy S, Dangman BC, McKenna BJ, Brien T, Ilves R. Bronchioloalveolar carcinoma in a child with congenital cystic adenomatoid malformation. Chest. 1997;112:548-51. 